\title{
Evaluating a simulation-based telecare training program for home healthcare professionals: A trainee perspective
}

\author{
Veslemøy Guise * Siri Wiig \\ Department of Health Studies, University of Stavanger, Stavanger, Norway
}

Received: October 29, 2016

DOI: $10.5430 /$ jnep.v7n5p76
Accepted: December 11, 2016 Online Published: December 28, 2016

URL: http://dx.doi.org/10.5430/jnep.v7n5p76

\begin{abstract}
Background: The provision and use of telecare services implies new ways of working for home healthcare staff. To gain the knowledge, skills and attitudes necessary for sound telecare practice, staff are in need of thorough training opportunities. Simulation has been suggested as a useful approach to prepare healthcare professionals for providing telecare services. The aim of this study was to test and evaluate a simulation-based telecare training program for qualified healthcare professionals and explore whether it met intended training objectives from the perspective of the trainees.

Methods: A total of 14 healthcare professionals working in home healthcare services participated in up to two training sessions, each across two separate days. Data were collected by way of four tape-recorded focus group interviews and field notes from non-participant observations of eight simulation sessions, and were analysed by way of systematic text condensation.

Results: The analysis resulted in seven categories addressing trainees' experiences of partaking in simulated virtual visits; their perceptions of simulation-based telecare training; and their views on the main learning outcomes from the simulation-based training program in question.

Conclusions: Simulation-based training provides trainees with realistic insight into the knowledge and skills required for new ways of working through telecare and can thus be a useful way of preparing healthcare professionals for the delivery of telecare services such as virtual home healthcare visits.
\end{abstract}

Key Words: Simulation, Simulation-based training, Vocational training, Telecare training, Telecare implementation, Home healthcare services

\section{INTRODUCTION}

Traditional home healthcare services are changing. The use of telecare technologies that enable healthcare professionals to remotely care for patients is becoming an increasingly common means of providing a range of home healthcare services. The provision of telecare implies new ways of working for healthcare professionals, ${ }^{[1]}$ in which staff must simultaneously integrate clinical competencies, communication skills, and technological skills. ${ }^{[2]}$ The implementation of telecare services therefore necessitates formal training for staff to facilitate adaptation of traditional home healthcare practices and encourage safe and appropriate care processes. ${ }^{[3-8]}$ Little research has however been done on what type of training is suited to telecare practice and how best to provide this training. ${ }^{[9]}$ There is some indication, though, that simulationbased training may be useful in preparation for telecare prac-

\footnotetext{
${ }^{*}$ Correspondence: Veslemøy Guise; Email: veslemoy.guise@ uis.no; Address: Department of Health Studies, University of Stavanger, NO 4036 Stavanger, Norway.
} 
tice, particularly in undergraduate nursing education..$^{[2,10-13]}$ The potentials in using simulation for vocational telecare training for home healthcare professionals have remained largely unexplored ${ }^{[14]}$ however, despite recognition of its utility both in preparation for changing work processes ${ }^{[15]}$ and the introduction of new technologies in healthcare organizations. ${ }^{[16]}$

Simulation-based training is increasingly being used to teach a range of knowledge, skills and attitudes relevant to healthcare provision in community care environments, including home healthcare settings. ${ }^{[17]}$ The benefits of simulation are many. Simulation has for example been noted to contribute to the development and promotion of essential nursing competencies such as clinical assessment and diagnostic skills, comprehensive interpersonal and communication skills, self-esteem, self-efficacy and confidence, ethical insight and empathy, and critical thinking abilities. ${ }^{[18]}$ Furthermore, research consistently shows that home healthcare trainees report high satisfaction with simulation as a teaching method, ${ }^{[19]}$ independent of the type of simulation modality used. In particular, participation in simulated home visits is extensively linked to an increased understanding of, preparedness for, and confidence in providing healthcare services in the home environment. ${ }^{[17,20-28]}$ Simulation is therefore recommended as a valuable means of rehearsing independent decision-making and successful problem solving in preparation for practice in complex and diverse home healthcare settings. ${ }^{[17,20,25,26]}$

Simulation has also been suggested as a valuable teaching strategy in connection with the increasingly common application of telecare technologies in home healthcare services. ${ }^{[25]}$ Home healthcare professionals have indeed expressed a desire for the practical, hands-on training offered by simulation-based approaches in preparation for telecare provision. ${ }^{[29]}$ There have however been very few reports of simulation-based telecare training initiatives aimed at qualified healthcare professionals. ${ }^{[30]}$ We have found one such study, by Rutledge and colleagues, ${ }^{[12]}$ which notes positive outcomes in using standardized patient simulations to introduce registered nurses to remote nursing care via audiovisual technology. In addition, a handful of studies have found simulation to be a useful approach to telecare training aimed at pre-registration nursing students. Reierson, Solli and Bjørk ${ }^{[2]}$ found that role-play simulation was a valuable way of introducing students to remote nursing care via real-time audio-visual technology, and that students reported feeling enthusiastic about this novel way of providing care. Similarly, Benhuri ${ }^{[10]}$ found that simulation helped students feel comfortable with telenursing technology and remote nursing care, while Tschetter, Lubeck and Fahrenwald ${ }^{[11]}$

Published by Sciedu Press observed that simulation-based training using human patient simulators improved students' confidence in using new technology. In addition, Mennenga and colleagues ${ }^{[13]}$ note that knowledge of telehealth was increased after participation in simulation scenarios using standardized patients, though what this knowledge consists of is not made clear.

Although there is now growing interest in research on telecare training, further studies are needed on the use of simulation to prepare home healthcare professionals for sound telecare practice. ${ }^{[2]}$ In an effort to expand the knowledge on whether and how simulation can best be utilized for this purpose, a simulation-based telecare training program for healthcare professionals ${ }^{[14]}$ was developed, tested and evaluated with staff working in municipal home healthcare services in Norway. The aim of this study was to assess trainee opinions of the form and content of the training program and explore if it met intended training objectives in relation to preparing home healthcare staff for undertaking virtual visits. Virtual home healthcare visits involve real-time audio-visual communication between healthcare professionals and patients through a secure video communication system. It was also of interest to explore how trainees experienced the simulated virtual visits, as the majority of them were unfamiliar with this form of service provision.

Specifically, the research questions were:

(1) How did trainees experience the simulated virtual visits?

(2) How was simulation-based training evaluated by the telecare trainees?

(3) What were the main learning outcomes from the simulation-based telecare training program?

\section{MethodS}

The study was part of an action research project called Safer@Home-Simulation and training, ${ }^{[31]}$ which was concerned with the development, test and evaluation of a simulation-based vocational training initiative for qualified healthcare professionals in preparation for undertaking virtual home healthcare visits. The study described here was undertaken as part of the implementation, evaluation and refinement stages of a five-phase action research process (diagnosis, action-planning, implementation, evaluation, and refinement) adapted from Susman and Evered. ${ }^{[32]}$ The implementation phase was concerned with the testing of the training program with a sample of healthcare professionals in two Norwegian municipalities intending to implement virtual visits for service users living at home. The concurrent evaluative phase entailed an exploratory assessment of participants' opinions on course form and content, including an 
exploratory evaluation of learning outcomes and whether the training program met intended training objectives from the perspective of the trainees. ${ }^{[33]}$

\subsection{Description and implementation of the simulation- based telecare training program}

The simulation-based training program was designed and developed in active collaboration with prospective trainees and other organizational representatives including managerial staff. ${ }^{[14,29]}$ The main training objectives were to gain knowledge and practical experience of how to undertake clinical tasks via virtual home healthcare visits, including how to prepare, initiate, conduct and end visits; application of relevant communication principles and techniques; and practical understanding and experience of relevant technical equipment. The training content consisted of a course curriculum; two course manuals; and five simulation scenarios (see Guise and Wiig ${ }^{[14]}$ for details). The simulation scenarios were developed in accordance with the approach to simulation-based training reported by Dieckmann. ${ }^{[34]}$ The chosen simulation modality was peer role-play, an approach that allows trainees practical insight into both the patient's and the professional's role during the telecare interaction. ${ }^{[35,36]}$ The training was delivered across two half-day training sessions between March and September 2015. Trainees from both municipalities trained separately with their own colleagues on both days. Training session 1 (Day 1) was held at a local simulation centre, while training session 2 (Day 2) took place in situ at each respective home healthcare organization. See Table 1 for information on the key components of the training sessions, including pre- and post-simulation activities, and how they were implemented.

Table 1. Key components of the simulation-based training course ${ }^{[49]}$

\begin{tabular}{|c|c|c|c|}
\hline Training component & Timing & Contents & Purpose \\
\hline $\begin{array}{l}\text { Course manuals sent } \\
\text { to trainees }\end{array}$ & $\begin{array}{l}\text { One week prior to } \\
\text { the first training } \\
\text { session }\end{array}$ & $\begin{array}{l}\text { Introduction to simulation, and Introduction to } \\
\text { core competencies for virtual visits }\end{array}$ & $\begin{array}{l}\text { Introduce trainees to the purpose and } \\
\text { contents of the training course }\end{array}$ \\
\hline $\begin{array}{l}\text { Introduction to the } \\
\text { course and the setting }\end{array}$ & $\begin{array}{l}\text { At the start of the } \\
\text { training session } \\
\text { ( } 20 \text { minutes) in } \\
\text { plenary }\end{array}$ & $\begin{array}{l}\text { Overview of course aims and objectives; } \\
\text { trainee reflections on experiences and course } \\
\text { expectations }\end{array}$ & $\begin{array}{l}\text { Introduction and preparation of trainees, } \\
\text { setting the learning environment, } \\
\text { establishing group norms }\end{array}$ \\
\hline $\begin{array}{l}\text { Introduction to } \\
\text { technical equipment }\end{array}$ & 15 minutes plenary & $\begin{array}{l}\text { Introduction to and testing of central functions } \\
\text { of the audio-visual equipment required for } \\
\text { undertaking virtual visits }\end{array}$ & $\begin{array}{l}\text { Hands-on introduction of trainees to } \\
\text { relevant technical equipment in } \\
\text { preparation for using virtual visits }\end{array}$ \\
\hline $\begin{array}{l}\text { Introduction to virtual } \\
\text { visits }\end{array}$ & 15 minutes plenary & $\begin{array}{l}\text { Core competencies related to virtual visits, } \\
\text { with emphasis on communication strategies } \\
\text { and techniques }\end{array}$ & $\begin{array}{l}\text { Introduce and prepare trainees for } \\
\text { engaging in simulated virtual visits }\end{array}$ \\
\hline $\begin{array}{l}\text { Introduction to } \\
\text { simulation }\end{array}$ & 20 minutes plenary & $\begin{array}{l}\text { Introduction to simulation-based learning and } \\
\text { the steps involved in a simulation session }\end{array}$ & $\begin{array}{l}\text { Introduce and prepare trainees for } \\
\text { engaging in simulation activities }\end{array}$ \\
\hline \multirow{3}{*}{ Simulation activities } & \multirow{3}{*}{$\begin{array}{l}60-90 \text { minutes in } \\
\text { groups } \\
\text { (30-45 minutes for } \\
\text { each scenario case) }\end{array}$} & $\begin{array}{l}\text { Briefing (10-15 mins): Introduction of scenario } \\
\text { case and its learning objectives, including the } \\
\text { patient's clinical presentation, work tasks, and } \\
\text { required equipment }\end{array}$ & $\begin{array}{l}\text { Ensure that trainees are familiar with the } \\
\text { scenario's patient case and its objectives, } \\
\text { the setting, and any necessary equipment }\end{array}$ \\
\hline & & $\begin{array}{l}\text { Simulation of scenarios (10-15 mins): trainees } \\
\text { play out the scenario case with the support of a } \\
\text { hands-off facilitator }\end{array}$ & $\begin{array}{l}\text { To conduct the scenario according to the } \\
\text { noted objectives; and to create a common } \\
\text { experience for subsequent debriefing }\end{array}$ \\
\hline & & $\begin{array}{l}\text { Debriefing (15-25 mins): Group discussion and } \\
\text { reflection on the case as it played out and } \\
\text { trainees' experiences of participating, actively } \\
\text { steered by the facilitator with attention to } \\
\text { intended learning objectives }\end{array}$ & $\begin{array}{l}\text { To encourage trainee reflection and } \\
\text { learning on the use of virtual visits in the } \\
\text { home healthcare services }\end{array}$ \\
\hline Course ending & $\begin{array}{l}\text { At the end of the } \\
\text { training session } \\
\text { ( } 20 \text { minutes } \\
\text { plenary) }\end{array}$ & $\begin{array}{l}\text { Brief course summary; trainees' reflections on } \\
\text { participation and learning outcomes; plan for } \\
\text { subsequent application of learning points in } \\
\text { practice }\end{array}$ & $\begin{array}{l}\text { To encourage trainees to apply relevant } \\
\text { learning points in practice at their own } \\
\text { places of work; to enable improvements } \\
\text { to and refinement of course content and } \\
\text { approach }\end{array}$ \\
\hline
\end{tabular}

The same two simulation scenarios were used on both training days with both trainee groups. Each scenario was thus enacted four times, twice in each municipality. Both scenario cases focused on teaching correct virtual visit procedure and effective communication at a distance. In addition, each scenario had learning objectives related to one or more specific 
clinical care tasks. For scenario $1(\mathrm{~S} 1)$, this was guidance of self-medication at a distance, whereas scenario 2 (S2) was concerned with nurse supervision of autonomous blood glucose measurement and the administration of insulin. At the start of each pre-simulation briefing, all trainees were allocated to either an active role as a patient, family carer or nurse, or an observational role. During the enactment of the scenario, the trainee playing the nurse was expected to undertake appropriate care tasks according to stated objectives. During the subsequent debriefing session, all trainees were expected to appraise the scenario in line with the objectives. All simulation sessions were facilitated by a simulation expert from the simulation centre.

Each scenario case also featured mock patient notes with information on medical history, current health status and psychosocial circumstances. These were intended to be consulted by trainees during the briefing to facilitate the necessary context to achieve a realistic enactment of the simulation scenario. ${ }^{[35]}$ After the initial training day, however, trainees requested more detailed information be added and the mock patient notes were therefore revised prior to the second training session in an effort to further increase the overall fidelity of the nurse-patient interactions in the scenario cases.

\subsection{Participants and data collection}

In total, 14 individuals working in two municipal home healthcare organizations participated in the training program. Across the two training days, there were seven participants from each municipality. Trainees were grouped according to their respective workplace within Municipality A or Municipality B. Managers from each municipality were responsible for recruiting staff members for training. Originally, it was intended that the same trainees would attend both training sessions, however, for various practical reasons, only six of the 14 were able to attend both days. Three participants attended only Day 1, while five attended only Day 2. See Table 2 for an overview of the number of individual participants involved on each respective training day in each municipality. The total sample consisted of 13 women and one man with a mean age of 43.2 years (a range of 27-56). A majority of participants were registered nurses. The mean length of work experience was 16.7 years (a range of 5-35 years). Only five trainees had used video communication technology for work purposes; three had tried it with patients while two had used it with colleagues.

Table 2. Number of trainees across training sessions

\begin{tabular}{|c|c|c|c|c|c|c|}
\hline \multirow{2}{*}{\multicolumn{2}{|c|}{ Training session }} & \multicolumn{4}{|l|}{ Trainees } & \multirow{3}{*}{$\begin{array}{l}\begin{array}{l}\text { Total } \\
\text { number of } \\
\text { trainees }\end{array} \\
5\end{array}$} \\
\hline & & \multirow{2}{*}{$\begin{array}{l}\begin{array}{l}\text { Registered } \\
\text { nurse }\end{array} \\
4\end{array}$} & \multirow{2}{*}{$\begin{array}{l}\begin{array}{l}\text { Auxilliary } \\
\text { nurse }\end{array} \\
-\end{array}$} & \multirow{2}{*}{$\begin{array}{l}\text { Professional } \\
\text { development manager } \\
1\end{array}$} & \multirow{2}{*}{$\begin{array}{l}\text { Home healthcare } \\
\text { service manager } \\
\text { - }\end{array}$} & \\
\hline \multirow{3}{*}{ Day 1} & Municipality A & & & & & \\
\hline & Municipality B & 3 & - & 1 & - & 4 \\
\hline & Total & 7 & - & 2 & - & 9 \\
\hline \multirow{3}{*}{ Day 2} & Municipality A & 3 & - & 1 & $2 *$ & 6 \\
\hline & Municipality B & 2 & $1 *$ & $1 *$ & $1 *$ & 5 \\
\hline & Total & 5 & 1 & 2 & 3 & 11 \\
\hline \multirow{3}{*}{$\begin{array}{l}\text { Total across } \\
\text { both days\# }\end{array}$} & Municipality A & 4 & - & 1 & 2 & 7 \\
\hline & Municipality B & 3 & 1 & 2 & 1 & 7 \\
\hline & Total & 7 & 1 & 3 & 3 & 14 \\
\hline
\end{tabular}

*New participants who did not attend Day 1 training session; \#The numbers here do not add up to the sum total for Days 1 and 2 as some trainees ( $\mathrm{n}=6$ ) attended both days

Data collection was undertaken on both training days in both municipalities, thus, data were collected across four training sessions in total. The data material consists of four focus group interviews conducted on Day 1, two with each trainee group (one done before and one done after the delivery of the training program with each respective group). Topics covered in the focus group interviews were expectations and experiences regarding participation in simulated virtual visits, and expectations of, and initial reactions to, undertaking simulation-based telecare training. In addition, the data material features field notes collected via non-participant

Published by Sciedu Press observation of all eight simulation sessions undertaken with both groups during both training days, with a particular focus on the reflective debriefing activities. ${ }^{[37]}$ Each simulation session lasted around 45 minutes, so in total the observations lasted six hours.

\subsection{Ethical approval}

The study has ethical approval from the Norwegian Social Science Data Services (NSD) (Ref. 32934, 16 April 2013). Participation was voluntary and written informed consent was obtained from all participants. All data have 
been anonymized and securely stored.

\subsection{Data analysis}

All focus group interviews were tape-recorded and transcribed verbatim. The focus group data and the data from the field notes were all analysed using systematic text condensation. ${ }^{[38]}$ This is an approach that involves the following steps: (1) establishing an overall impression of the data material and identifying preliminary themes; (2) identifying and sorting units of meaning into code groups; (3) condensing the contents of each of the coded groups into subgroups; and (4) summarizing the contents of each code group into categories, in order to generalize descriptions and concepts. Two themes with relevance to the research questions are reported in this article (Reflections and thoughts on undertaking virtual visits and Reflections and thoughts on participating in simulation-based learning). The analytical steps, including examples of meaning units according to subgroups and final categories are presented in Table 3.

\section{RESUlts}

The analysis resulted in seven categories. Four of them correspond with how trainees experienced the simulated virtual visits, in which participants discussed their initial impressions of undertaking virtual visits and reflected specifically on the differences in the experience of being in the nurse versus the patient role during virtual visits. In addition, they discussed potential benefits and possible challenges of using virtual visits in home healthcare services. One category corresponds with how simulation-based training was evaluated by telecare trainees, focusing on the utility of simulation in preparation for undertaking virtual visits. Finally, there are two categories that correspond with the main learning outcomes from simulation-based training, focused on communication skills and appropriate preparation for virtual visits. These findings are described in more detail below. See Table 3 for illustrative quotes from the focus group interviews and/or field notes from the non-participant observations.

\subsection{Virtual visits are comparable to conventional prac- tice}

Participants found their first few attempts at undertaking simulated virtual visits to be a fun and positive experience. Many had been eagerly anticipating the training sessions and were happy to finally be able to get a feel for virtual visits and how to undertake work tasks in this way. In their initial assessments of virtual visits, the majority of participants compared them favorably to a physical visit or a phone call, which are the most common forms of traditional patient contact in the home healthcare services. Several trainees also noted that virtual visits made them feel as 'close' to the patient as a physical visit would. In comparison to phone calls, virtual visits were viewed even more favorably, as they were seen to allow for a more personal connection with the patient, making them more versatile than a traditional phone call. While most participants were encouraged by discovering that several aspects of virtual visits were comparable to conventional practice, some participants did find the practice around virtual visits to be initially unfamiliar. However, they were reassured that with time, this would be overcome with training and experience.

\subsection{The nursing role and the patient role offer contrast- ing experiences}

The trainees' experiences of being in the role of the nurse versus that of the patient offered contrasting perspectives on participating in virtual visits. The main difference between the two roles was that playing the patient and seeing the nurse on the screen felt 'very close', while seeing the patient on the screen as the nurse felt 'far away'. This latter experience of feeling distant made some trainees insecure about being able to adequately care for the patient without being physically present in the patient's home. In contrast, the majority of those playing the patient role expressed feeling 'safe' and 'really well cared for'. These opposing experiences of partaking in the virtual visits were largely explained by reference to the professional demands and responsibilities of the nurse in the encounter. In light of these experiences, participants acknowledged that insight into both roles and perspectives was essential to get a comprehensive picture of what it is like to partake in virtual visits, and that patients would feel that the staff are present despite the physical distance between them.

\subsection{Virtual visits have potential to improve service pro- vision}

Participants saw a potential in the use of virtual visits to improve several aspects of current home healthcare service provision. Firstly, there was a general consensus that the use of virtual visits would free up or save time compared to conventional practice, allowing for more efficient ways of working. Furthermore, there was a view that virtual visits would allow for a more punctual and thus more predictable service for patients, which was seen as a clear improvement on existing practice, where complaints about the short, rushed and unpredictable nature of physical visits were reportedly common. Secondly, virtual visits were seen to encourage more active and independent patients better able to become involved in their own care routines. Trainees admitted that they currently would often do things like fetch water or open medicine dis- 
pensers and count pills for patients, even when this was not necessary since they could manage it for themselves. The use of virtual visits was therefore regarded as a means of enabling more participation and responsibility for own care among patients.

Table 3. Analytical process and categories

Meaning units (selected)
The entire virtual visit went really well, I didn’t notice anything negative
about it.
It is very similar to a phone call, but you also get that clinical gaze, you get
more of a connection [to the patient].

more of a connection [to the patient].

This can work well, once we get some experience with it. When we get to know the user and the equipment.

Seeing the patient on the screen as the nurse, it felt far away.

I was positively surprised at how present [the nurse] felt. I felt cared for, that [she] saw me. That she took me seriously.

It is essential to try out both sides [of the interaction] to see what it's like. This will save a lot of time. We can manage more visits in a shorter time.

Many of the things we usually do [like opening the medicine dispenser and counting the pills] we now have to ask the service users to do. The patient actually has to do it himself now.

I didn't feel sure that he had taken the correct pill.

There is a challenge in that the technology will not work properly. If we are to give good nursing care, the technical issues must be completely sorted. It was good to try it and become a bit more confident in what it is like to have a conversation with a user through a screen. It is important to practice and get a feel for that responsibility.

It [simulation] is a great opportunity to develop yourself, to observe, to become aware of how one speaks and uses body language. It is very educational.

By trying it [virtual visits] in this way [through simulation] one gains better insight into who it may not be suitable for as well as those it suits. Speaking clearly and being precise. Like in the user's home, but even clearer.

To show genuine interest in the patient and that you are willing to listen. Give them time to speak, don't interrupt.

I was struck by how much my facial expressions and body language mean for conveying confidence and a calm presence [for the patient].

One lesson learnt is to look at the camera and not at the screen. To be aware of the right angle of one's gaze to create good contact with the patient. We should have a thorough description of specific virtual visit tasks in each patient's notes, to be as prepared as possible.

A checklist next to the PC would be helpful.

Knowing that things do not always go as expected. Things will always come up that you haven't thought of. That's what nursing is like.

Subgroups $\quad$ Categories

A positive experience

Positive comparison to traditional forms of patient contact

Virtual visits are comparable to conventional practice

Virtual visits will work well with time

Felt distant as the nurse

Felt close and well cared for as the patient

The nursing role and the patient role offer contrasting experiences

Insight into both roles is essential

Virtual visits are a time saver

Virtual visits enable more active and independent patients

Lack of control over medications

Technical problems are a worry

Possible challenges in undertaking virtual visits

Simulation gives insight into a new way

of communicating

Simulation creates awareness of self

Simulation provides useful insight into a new way of working

Simulation gives insight into who virtual visits are suited for

Importance of clear and precise verbal communication

Importance of genuinely listening

Importance of conveying presence

Virtual visits necessitate comprehensive communication skills

Awareness of own gaze

Having access to all necessary information

Having access to a common procedura checklist

Be prepared to take things as they come
Successful virtual visits necessitate appropriate preparation 


\subsection{Possible challenges in undertaking virtual visits}

Participants also discussed possible challenges related to the use of virtual visits. Two issues in particular were of concern, namely a perceived lack of usual control over the administration of medications, and potential problems related to the technical equipment. Regarding the first issue, several trainees expressed concern about not being sure whether the patient had taken the correct type or dosage of medication during the scenario. Good routines for medication checks were therefore noted as extra important during virtual visits. However, it was pointed out that a lack of control over medications can pose challenges during patient encounters in traditional practice settings too, and that it will sometimes be 'a guess' as to whether or not the patient has taken their medication prior to the nurse's arrival to the home. In addition, participants were worried about potential technical problems with either the internet access or the audio-visual communication equipment itself. Trainees were very clear, therefore, that their ability to provide good quality healthcare via virtual visits is very much contingent on whether the picture and sound quality and the internet connection are up to a reliable standard.

\subsection{Simulation gives useful insight into a new way of working}

Trainees found simulation-based training to be an enjoyable and useful way of learning how to undertake virtual visits. Several participants talked about the value of getting a realistic chance to gain insight into and practice a new means of communicating before using virtual visits with actual patients, to help them feel secure and confident about this way of providing care. Participants also found that simulation was useful in creating self-awareness and aiding reflection on how one comes across during the nurse-patient encounter. This was considered especially helpful in regard to working in new ways, but also in regard to enhancing awareness of self in traditional practice situations. In addition, participants noted that the simulation scenarios provided valuable insight into how to make best use of virtual visits as part of the overall provision of home healthcare services, by providing an indication of which patients would be suited to this type of service or not.

\subsection{Virtual visits necessitate comprehensive communica- tion skills}

When asked to reflect on the main lessons learned about virtual visits after participating in the simulation-based training program, most trainees mentioned the knowledge and awareness they had gained regarding the comprehensive set of communication skills necessary for delivering high quality nursing care at a distance. First and foremost, participants talked about the primary importance of clear and precise verbal communication, as well as the importance of genuinely listening to the patient and allowing them time to speak. In addition, the importance of being aware of how to convey presence through one's own facial expressions and body language was discussed. Lastly, participants noted the importance of maintaining awareness of where to focus one's gaze throughout the virtual visit. Many found it challenging to remember to look directly into the camera to uphold 'eye contact' with the patient, as opposed to being drawn to looking at the patient's face on the screen. Several participants therefore suggested using a visual cue next to the camera to remind themselves of where to place their gaze.

\subsection{Successful virtual visits necessitate appropriate preparation}

Apart from sound communication skills, the main learning outcome reported by trainees was the importance of being appropriately prepared to undertake virtual visits. A large aspect of feeling properly prepared was having access to necessary information about the patient and intended work tasks by way of detailed patient notes and thorough task descriptions applicable to each individual patient. This included knowing what medical equipment patients have at home, to be able to provide adequate guidance and instruction. The importance of having common procedures for all staff to follow during virtual visits was also noted, for example in the form of a common procedural checklist to use as needed. The need for a checklist was discussed during the post-training focus group on the first training day and was subsequently developed in collaboration with trainees for use on the second training day. It was modified slightly again after feedback from participants who used it on Day 2. Being prepared was also concerned with being able to 'take things as they come' during virtual visits and to 'be prepared to meet the unexpected'. Participants were therefore firm in the need to be calm and solution oriented in their approach, which they argued, is typical of the nursing profession regardless of how care is delivered.

\section{Discussion}

Simulation pedagogy has been recommended as a useful means of providing healthcare professionals with the understanding, skills and competencies required to undertake safe, high quality telecare practice, yet few examples of simulation-based telecare training have been described in the research literature. This evaluation study found that participants had a positive view of undertaking simulated virtual visits and compared them favorably to conventional modes of practice including physical visits and phone calls. Trainees were pleased to find that it was possible to provide satisfac- 
tory care and support at a distance from the patient. Reierson, Solli and Bjørk ${ }^{[2]}$ as well as Rutledge and colleagues ${ }^{[12]}$ have noted similar findings regarding positive perceptions of the value of telecare after participation in simulation-based training. Furthermore, based on their experiences with the simulations, trainees argued that virtual visits had the potential to improve the quality of current services for home healthcare patients. Notably, virtual visits were seen to facilitate more punctual and predictable services, which is a possible quality enhancing aspect of home healthcare services. ${ }^{[39]}$ In addition, participants suggested that virtual visits would likely encourage healthcare professionals to more readily support patient participation and self-care practices in homedwelling patients. This is another quality enhancing measure noted elsewhere. ${ }^{[39,40]}$ Further research should investigate if trainees hold the same opinions of the positive potential in virtual visits also after using them in real practice settings.

While the trainees in this study felt overall positive about virtual visits, some also expressed ambivalent feelings about the initial experience. Most notable was the contrasting experience of feeling far away from the patient when playing the nurse in the telecare encounter, yet feeling close to the nurse and thus well cared for when playing the patient. This is somewhat opposite of previous research findings, where telecare students reported feeling as close to the patient during the simulated telecare encounter as they did during a traditional face-to-face encounter. ${ }^{[12]}$ One explanation for this discrepancy in findings could be the topics of the scenarios enacted and the care tasks concerned within each respective scenario case. In future, simulation-based telecare training initiatives should implement a more diverse range of scenario cases to enable assessment of whether and how particular simulation scenarios may influence trainees' impressions of the telecare experience.

Trainees also noted some potential practical difficulties related to undertaking virtual visits, which were centered on possible problems with the technical equipment concerned, as well as a perceived lack of control over the administration of medications. Regarding the first issue, it has indeed been found that technical problems and poor device quality can adversely affect the quality and safety of telecare services. ${ }^{[30]}$ As this is doubtless a very real concern for healthcare professionals faced with the implementation and use of telecare services, ${ }^{[8]}$ it needs to be taken seriously by home healthcare managers, telecare implementation managers, and technology providers alike. In regard to the second concern, the participants themselves were quick to note that the potential for medication errors, where patients miss a dose, take it at the wrong time, take an incorrect dose, or the incorrect medication, is not exclusive to the telecare context but rather a

Published by Sciedu Press very common patient safety issue within the home healthcare setting in general. ${ }^{[41-43]}$ The importance of implementing good routines for medication checks is essential also in the provision of telecare, as was discussed by participants.

In line with previous research findings, ${ }^{[19]}$ the home healthcare professionals in this study expressed enthusiasm for and satisfaction with simulation as a teaching method. Trainees noted that simulation gave them realistic insight into a new way of working and improved their confidence in providing remote nursing care. ${ }^{[10,11]}$ Simulation was useful in regards to increasing trainees' practical knowledge of sound telecare provision, specifically regarding gaining awareness of how one comes across during the telecare encounter. It also gave an improved understanding of which patients are best suited to receive telecare services, and the importance of being able to adequately assess patient suitability for taking part in telecare. Ability to identify and continually assess suitable patients is an important patient safety consideration for healthcare professionals looking to adopt telecare practice, ${ }^{[39]}$ and has been identified as a crucial would-be component of telecare training for home healthcare staff. ${ }^{[8]}$ Our findings indicate that simulation-based training may be able to contribute valuable knowledge to enable staff to make easier, more confident assessments of patient suitability for a particular telecare service.

Furthermore, the findings indicate the utility in peer role-play simulation to enable trainees to experience both the patient's and the healthcare professional's side of the same case scenario. Not only does this approach promote trainee awareness and understanding of the complexities of the patientprofessional interaction, ${ }^{[35,36]}$ it also provides trainees with important insight into the patient's concerns and emotions. ${ }^{[44-46]}$ In addition, this simulation modality can be initiated without requiring a huge amount of resources and is thus relatively cost-effective. ${ }^{[47]}$

To evaluate whether the training program managed to meet the intended training objectives, participants were asked after each respective simulation session what they considered were the main lessons learned. According to trainees, overall learning outcomes were two-fold. Firstly, the importance of being able to apply a comprehensive set of communication skills to successfully engage in virtual visits, and secondly, the necessity of being suitably prepared, practically and mentally, for undertaking each individual virtual visit. As both sets of learning outcomes identified correspond to intended training objectives, including how to properly prepare for and conduct a visit, and how to apply relevant communication principles and techniques, it can be argued that these were successfully met, ${ }^{[33]}$ at least in a short-term capacity. The 
fact that trainees did not reflect on technical competencies as a learning outcome could imply that this aspect of knowing how to conduct virtual visits is not an immediate concern, with the focus instead on adaptation and application of traditional nursing competencies such as clinical procedural and communicative skills, as noted by Nagel and colleagues. ${ }^{[7]}$

\section{Limitations}

This study has some limitations. As it is a small-scale study, the results should be interpreted with some caution. A larger study, with more participants from additional municipalities, or where data was collected over a longer period of time featuring more training days and/or utilizing different scenario cases, could have produced different results. Furthermore, this study has only evaluated simulation-based telecare training in so far as it has explored trainee assessment of the training approach and the learning outcomes associated with it. This lack of a more comprehensive type of evaluation is a known weakness in studies on organizational training. ${ }^{[48]}$

\section{Conclusions}

The findings of this study support the notion that simulationbased training can be a valuable way of introducing healthcare professionals, as well as students, to remote care via real-time audio-visual technology. ${ }^{[2]}$ By providing realistic insight into new ways of working, particularly in relation to the adaptation of communication skills and clinical procedural competencies, simulation can provide hands-on preparation for a diverse range of telecare scenarios that healthcare staff are likely to encounter in real-life practice situations. Scenarios can indeed be customised to address actual needs in practice, as and when issues arise that require specific preparation and training. Findings also indicate that the use of peer role-play simulations may provide an added dimension of learning, in that it enables awareness of both the patient's and healthcare professional's experience of the telecare encounter. More research should be done to further investigate the benefits indicated here of using peer roleplay simulations in telecare training. Future, steps in the evaluation of simulation-based telecare training initiatives are to assess outcomes beyond trainee satisfaction with the approach. ${ }^{[24]}$ These include longer-term effects such as retention of learning outcomes over time, and the circumstances under which acquired knowledge and competencies are applied in real clinical practice. ${ }^{[19,27]}$ Research should also look into whether and how different forms of training can be said to affect organizational procedures and the quality of telecare services provided, as well as the extent to which staff training impacts patient outcomes.

\section{ACKNOWLEDGEMENTS}

The Safer@Home-Simulation and training study is part of the project 'Smart systems to support safer independent living and social interaction for elderly at home' (Safer@Home), supported by the Research Council of Norway (grant number 210799). We would like to thank all the trainees for their participation in the project. Thanks also to the other members of our research team, as well as staff at the SAFER Simulation Centre in Stavanger. Further thanks go to the funders and the overall Safer@Home project partners. Lastly, we would like to thank the reviewers for their valuable comments to improve the paper.

\section{CONFlicts OF INTEREST Disclosure}

The authors declare that they have no competing interests.

\section{REFERENCES}

[1] Nicolini D. The work to make telemedicine work: a social and articulative view. Soc Sci Med. 2006; 62: 2754-2767. http://dx.doi .org/10.1016/j.socscimed.2005.11.001

[2] Reierson IÅ, Solli H, Bjørk IT. Nursing students' perspectives on telenursing in patient care after simulation. Clinical Simulation in Nursing. 2015 Apr 30; 11(4): 244-50. http://dx.doi.org/10 $1016 /$ j.ecns.2015.02.003

[3] Carter L, Horrigan J, Hudyma S. Investigating the educational needs of nurses in telepractice: a descriptive exploratory study. Can J Univ Contin Educ. 2010 Mar 5; 36: 1-20. http://dx.doi.org/10.21 $225 / d 5 r p 4 b$

[4] Clark J, McGee-Lennon M. A stakeholder-centred exploration of the current barriers to the uptake of home care technology in the UK. Journal of Assistive Technologies. 2011 Mar 18; 5(1): 12-25. http://dx.doi.org/10.5042/jat.2011.0097
[5] Zanaboni P, Wootton R. Adoption of telemedicine: from pilot stage to routine delivery. BMC Medical Informatics and Decision Making. 2012 Jan 4; 12(1): 1. http://dx.doi.org/10.1186/1472-694 7-12-1

[6] Cresswell KM, Bates DW, Sheikh A. Ten key considerations for the successful implementation and adoption of large-scale health information technology. Journal of the American Medical Informatics Association. 2013 Jun 1; 20(e1): e9-13. http://dx.doi.org/10 . 1136/amiajnl-2013-001684

[7] Nagel DA, Pomerleau SG, Penner JL. Knowing, caring, and telehealth technology: "Going the distance" in nursing practice. J Holist Nurs. 2013 June 1; 31: 104-112. http://dx.doi.org/10.1177 /0898010112465357

[8] Taylor J, Coates E, Brewster L, et al. Examining the use of telehealth in community nursing: identifying the factors affecting frontline staff acceptance and telehealth adoption. Journal of Advanced Nursing 2015 Feb 1; 71(2): 326-37. http://dx.doi.org/10.1111/jan 
.12480

[9] Basu A, Seaton P, Kirk R, et al. Review of the effectiveness of educational tools for teaching telehealth care. Christchurch: University of Canterbury; 2010 May 25.

[10] Benhuri G. Teaching community telenursing with simulation. Clinical Simulation in Nursing. 2010 Aug 31; 6(4): e161-3. http: //dx.doi.org/10.1016/j.ecns.2009.11.011

[11] Tschetter L, Lubeck P, Fahrenwald N. Integrating QSEN and technology to address rural health care: initial outcomes. Clinical Simulation in Nursing. 2013 Oct 31; 9(10): e469-75. http://dx.doi.org/1 $0.1016 / j$.ecns . 2012.09.005

[12] Rutledge CM, Haney T, Bordelon M, et al. Telehealth: preparing advanced practice nurses to address healthcare needs in rural and underserved populations. International Journal of Nursing Education Scholarship. 2014 Jan 1; 11(1): 1-9. http://dx.doi.org/10.15 15/ijnes-2013-0061

[13] Mennenga HA, Johansen L, Foerster B, et al. Using simulation to improve student and faculty knowledge of telehealth and rural characteristics. Nursing Education Perspectives. 2016 Sep 1; 37(5): 287-8. PMid:27740564

[14] Guise V, Wiig S. Preparing for organizational change in home health care with simulation-based training. Clinical Simulation in Nursing. 2016 Nov 30; 12(11): 496-503. http://dx.doi.org/10.1016/j .ecns.2016.07.011

[15] Ruohomäki V. Simulation gaming for organizational development. Simulation \& Gaming. 2003 Dec 1; 34(4): 531-549. http://dx.d oi .org/10.1177/1046878103258203

[16] Aggarwal R, Mytton OT, Derbrew M, et al. Training and simulation for patient safety. Quality and Safety in Health Care. 2010 Aug 1; 19(Suppl 2): i34-43. http://dx.doi.org/10.1136/qshc. 2009 .038562

[17] Distelhorst KS, Wyss LL. Simulation in community health nursing: A conceptual approach. Clinical Simulation in Nursing. 2013 Oct 31; 9(10): e445-51. http://dx.doi.org/10.1016/j.ecns .20 12.07 .208

[18] Guise V, Chambers M, Välimäki M. What can virtual patient simulation offer mental health nursing education? Journal of psychiatric and mental health nursing. 2012 Jun $1 ; 19(5)$ : 410-8. http: //dx.doi.org/10.1111/j.1365-2850.2011.01797.x

[19] Smith SJ, Barry DG. The use of high-fidelity simulation to teach home care nursing. Western Journal of Nursing Research. 2013 Mar 1; 35(3): 297-312. http://dx.doi .org/10.1177/01939459114 17635

[20] Mole L, Scarlett V, Campbell M, et al. Using a simulated chaotic home environment for preparing nursing and social work students for interdisciplinary care delivery in a Scottish context. Journal of Interprofessional Care. 2006 Jan 1; 20(5): 561-3. http://dx.doi . org/10.1080/13561820600909837

[21] Richards EL, Simpson V, Aaltonen P, et al. Public health nursing student home visit preparation: The role of simulation in increasing confidence. Home Healthcare Now. 2010 Nov 1; 28(10): 631-8. http://dx.doi.org/10.1097/NHH.0b013e3181f85e10

[22] Yeager ST, Gotwals B. Incorporating high-fidelity simulation technology into community health nursing education. Clinical Simulation in Nursing. 2010 Apr 30; 6(2): e53-9. http://dx.doi.org/10. 1016/j.ecns. 2009.07.004

[23] Unsworth J, Tuffnell C, Platt A. Safer care at home: use of simulation training to improve standards. British Journal of Community Nursing. $2011 \mathrm{Jul} 1$; 16(7). http://dx.doi.org/10.12968/bjen. 2011. 16.7.334

[24] Kim-Godwin YS, Livsey KR, Ezzell D, et al. Home visit simulation using a standardized patient. Clinical Simulation in Nursing.
2013 Feb 28; 9(2): e55-61. http://dx.doi.org/10.1016/j.e cns. 2011.09.003

[25] Smith SJ, Barry DG. An innovative approach to preparing nursing students for care of the elderly in the home. Geriatric Nursing. 2013 Feb 28; 34(1): 30-4. http://dx .doi.org/10.1016/j.gerinur se.2012.07.001

[26] Center D, Faragher J, Bittner CA, et al. Simulated home care increases confidence and improves care transitions. The Journal of Continuing Education in Nursing. 2014 Jul 1; 45(7): 294-6. http://dx.doi.org/10.3928/00220124-20140625-14

[27] Gotwals B, Yeager ST. Improving the process of community-based student nurse practice through a high-fidelity simulated clinical experience. Nurse Educator. 2014 Jan 1; 39(1): 26-30. http://dx.doi . org/10.1097/NNE.0000000000000009

[28] Husson NM, Zulkosky K, Fetter M, et al. Integrating community health simulation scenarios: Experiences from the NCSBN National Simulation Study. Clinical Simulation in Nursing. 2014 Nov 30; 10(11): 581-6. http://dx.doi.org/10.1016/j.ecns. 2013.1 1.009

[29] Guise V, Wiig S. Perceptions of telecare training needs in home healthcare services: a focus group study. BMC Health Services Research. Forthcoming 2017.

[30] Guise V, Anderson J, Wiig S. Patient safety risks associated with telecare: a systematic review and narrative synthesis of the literature. BMC Health services Research. 2014 Nov 25; 14(1): 1. http://dx.doi.org/10.1186/s12913-014-0588-z

[31] Wiig S, Guise V, Anderson J, et al. Safer@Home-simulation and training: the study protocol of a qualitative action research design. BMJ Open. 2014; 4: e004995. http://dx.doi.org/10.1136/b mjopen-2014-004995

[32] Susman GI, Evered RD. An assessment of the scientific merits of action research. Administrative Science Quarterly. 1978 Dec 1; 23 582-603. http://dx.doi.org/10.2307/2392581

[33] Alvarez K, Salas E, Garofano CM. An integrated model of training evaluation and effectiveness. Human Resource Development Review. 2004 Dec 1; 3(4): 385-416. http://dx.doi.org/10.1177/153 4484304270820

[34] Dieckmann P. (Ed.) Using simulations for educations, training and research. 2009; Pabst Science Publishers, Lengerich. ISBN 978-389967-539-9.

[35] Joyner B, Young L. Teaching medical students using role play: twelve tips for successful role plays. Medical Teacher. 2006 Jan 1; 28(3): 225-9. http://dx.doi.org/10.1080/01421590600711252

[36] Bosse HM, Nickel M, Huwendiek S, et al. Peer role-play and standardised patients in communication training: a comparative study on the student perspective on acceptability, realism, and perceived effect. BMC Medical Education. 2010 Mar 31; 10(1): 1. http://dx.doi.org/10.1186/1472-6920-10-27

[37] Husebø SE, O'Regan S, Nestel D. Reflective practice and its role in simulation. Clinical Simulation in Nursing. 2015 Aug 31; 11(8): 368-75. http://dx.doi.org/10.1016/j.ecns. 2015.04.005

[38] Malterud K. Systematic text condensation: a strategy for qualitative analysis. Scandinavian Journal of Public Health, 2012; 40(8): 795-805. http://dx.doi.org/10.1177/1403494812465030

[39] Guise V, Husebø AML, Storm M, et al. Telecare in home healthcare services: implications for quality and safety. In K. Aase \& L. Schibevaag (Eds.), Researching patient safety and quality in health care: a Nordic perspective. 2016; Taylor \& Francis, Boca Raton. 179 p. http://dx.doi.org/10.1201/9781315605609-13

[40] Husebø AML, Storm M. Virtual visits in home health care for older adults. The Scientific World Journal. [Internet] 2014 Nov 20 [Cited 
2016 October 20]. Available from: http://dx.doi.org/10.1155 $/ 2014 / 689873$

[41] Mager DR. Medication errors and the home care patient. Home Healthcare Now. 2007 Mar 1; 25(3): 151-5. http://dx.doi.org $/ 10.1097 / 01$. NHH.0000263430.00438.b3

[42] Taylor DM, Robinson J, MacLeod D, et al. Therapeutic errors involving adults in the community setting: nature, causes and outcomes. Australian and New Zealand Journal of Public Health. 2009 Aug 1; 33(4): 388-94. http://dx.doi.org/10.1111/j.1753-6405. 2009.00413.x

[43] Mager DD, Madigan EA. Medication use among older adults in a home care setting. Home Healthcare Now. 2010 Jan 1; 28(1): 14-21. http://dx.doi.org/10.1097/01.NHH.000036 $6791.48658 . \mathrm{d} 2$

[44] Bosse HM, Schultz JH, Nickel M, et al. The effect of using standardized patients or peer role play on ratings of undergraduate communication training: a randomized controlled trial. Patient Education and Counseling. 2012 Jun 30; 87(3): 300-6. http: //dx . doi .org/10. $1016 / j \cdot$ pec . 2011.10.007
[45] Baile WF, Blatner A. Teaching communication skills: using action methods to enhance role-play in problem-based learning. Simulation in Healthcare. 2014 Aug 1; 9(4): 220-7. http://dx.doi.org/10. $1097 /$ SIH. 0000000000000019

[46] Bearman M, Palermo C, Allen LM, et al. Learning empathy through simulation: a systematic literature review. Simulation in Healthcare. 2015 Oct 1; 10(5): 308-19. http://dx.doi.org/10.1097/SIH .0000000000000113

[47] Bosse HM, Nickel M, Huwendiek S, et al. Cost-effectiveness of peer role play and standardized patients in undergraduate communication training. BMC Medical Education. 2015 Oct 24; 15(1): 183. http://dx.doi.org/10.1186/s12909-015-0468-1

[48] Coultas CW, Grossmann R, Salas E. Design, delivery, evaluation, and transfer of training systems. In G. Salvendy (Ed.). Handbook of human factors and ergonomics (4th ed.). 2012; John Wiley \& Sons, Hoboken, 490 p. http: //dx . doi .org/10.1002/9781118 131350. $\operatorname{ch} 17$

[49] Aase I, Aase K, Dieckmann P, et al. Interprofessional communication in a simulation-based team training session in healthcare: A student perspective. Journal of Nursing Education and Practice. 2016 Jul 1; 6(7): 91. http://dx.doi.org/10.5430/jnep.v6n7p91 